\title{
MONITORING OF ENGINEERING BUILDINGS BEHAVIOUR WITHIN THE DISASTER MANAGEMENT SYSTEM
}

\author{
G. Oku Topal a*, E. Gülal ${ }^{\mathrm{a}}$ \\ a YTU, Civil Engineering Faculty, Dept. of Geomatic Engineering, Davutpaşa Campus, Istanbul, Turkey - \\ (guloku,egulal)@yildiz.edu.tr
}

KEY WORDS: Structural monitoring, GPS, Shaking table

\begin{abstract}
:
The Disaster management aims to prevent events that result in disaster or to reduce their losses. Monitoring of engineering buildings, identification of unusual movements and taking the necessary precautions are very crucial for determination of the disaster risk so possible prevention could be taken to reduce big loss. Improving technology, increasing population due to increased construction and these areas largest economy lead to offer damage detection strategies. Structural Health Monitoring (SHM) is the most effective of these strategies. SHM research is very important to maintain all this structuring safely. The purpose of structural monitoring is determining in advance of possible accidents and taking necessary precaution. In this paper, determining the behaviour of construction using Global Positioning System (GPS) is investigated. For this purpose shaking table tests were performed. Shaking table was moved at different amplitude and frequency aiming to determine these movement with a GPS measuring system. The obtained data were evaluated by analysis of time series and Fast Fourier Transformation techniques and the frequency and amplitude values are calculated. By examining the results of the tests made, it will be determined whether the GPS measurement method can accurately detect the movements of the engineering structures.
\end{abstract}

\section{INTRODUCTION}

With the improving technology, increasing population due to increased construction and these areas largest economy cause to offer damage determination strategies like Structural Health Monitoring (SHM) within the scope of the disaster management system. Determination of the disaster hazard of big engineering construction is very important in terms of reducing possible losses. Observation of the critical changes on the buildings and determination of damage can be done with systematic health monitoring. As a result of these observations, it is very important to make necessary reinforcements in structures that have reached their design lifetimes or are found to be highly damaged in terms of reducing post-disaster losses. It is seen that dozens of different methods and equipment are used in SHM applications. But nowadays it is seen that Global Positioning Systems (GPS) are used intensively in the observation of dynamic deformations in order to determine the structural vibrations for structures such as long bridges, towers, high buildings (Im et al., 2013). With the help of the developed GPS method, SHM studies have gained a new dimension and become based on a current observation with the help of data obtained simultaneously (Wells et al., 1987).

The main topic of this study was the determination of the capacity to determine the structural vibrations of GPS by the shake table tests, which was the subject of many researchers. A study of Wang et al.'s work after the 2010 Chile Earthquake is one of the key tests in this area. Their studies have shown that GNSS receivers have a great potential in determining the horizontal motion of an observation point (Wang et al., 2012). In addition, harmonic and random movements were created in Önen et al. , which was performed with a uniaxial shaking table, and the results obtained by comparing GPS, accelerometer and LVDT results of these movements were examined (Önen et al., 2014).
In our study, the results of the GPS measurements performed with the single axes shake table will be analysed using Time Series and Fast Fourier Transform Analysis.

Although there are many different GPS measurement methods, RTK (Real Time Kinematic) GPS measurement methods FKP (Flächen Korrektur Parameter) and VRS (Virtual Reference Station) measurement methods will be used at this stage of our study. This is because RTK GPS measurement method is used most effectively and practically in today's engineering works. VRS and FKP methods are the most commonly used RTK measurement methods.

\section{METHOD AND MATERIAL}

In order to take the necessary precautions in the context of disaster management system, Health Monitoring (HM) was chosen as the main subject of this study and open field tests were carried out in this context. Following the results of applications performed with shake table using Global Positioning (GPS) technique, which is one of the alternative approaches in SHM, it is being investigated whether this method can be effectively used in health monitoring studies. Shaking table is a platform that imitates earthquake movements by artificially producing vibrational movements. So simulations of earthquake motion is carried out through this table. The building model to be tested is placed on the shaking table and subjected to ground motion to observe the dynamic behaviour. But in this study, the RTK GPS data which is mounted on the shaking table was evaluated (Figure 1).

The results of GPS measurements were compared with the position sensor (LVDT) of the shake table by moving the shake table at specific amplitudes and frequencies. In this study RTK GPS methods VRS and FKP methods will be evaluated and compared separately. 


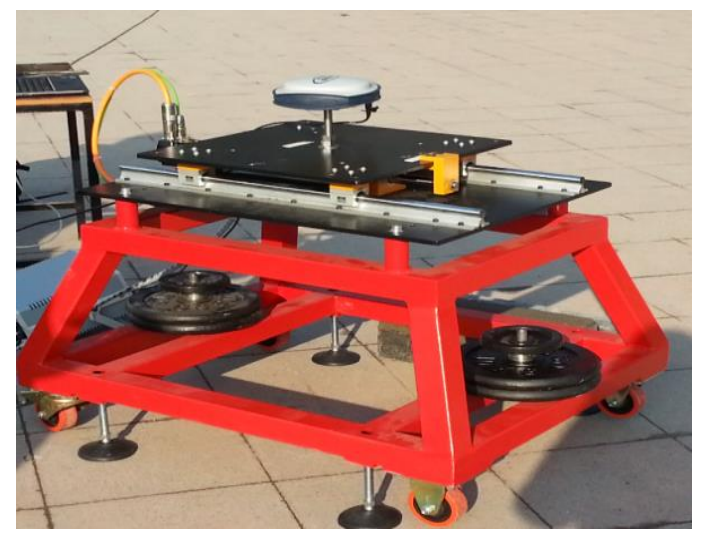

Figure 1. Shaking Table

The basic principle in the VRS method is to create a virtual station in the vicinity of the roaming receiver, and the location of the roaming receiver is determined with the help of this virtual station. In this method, the position of the mobile receiver must be known approximately and is obtained by these code measurements. The virtual reference station is created near the mobile receiver and the dependent errors are eliminated (Arslan et al., 2002).

FKP (Area Correction Parameters Method) is the same as the basic principle VRS method. Here too, the transfer of data at the reference stations to the browsing receiver requires that the approximate location of the browsing receiver be known. In the area correction parameters method, surfaces are used as references in the calculation of correction parameters (Eren, K., Uzel, T., Gülal, E., Yıldırım, O. and Cingöz, A., 2009).

Experiment was carried out by mounting the Spectra Precision SP80 GNSS Receiver on the shaking table in the application area of Yıldız Technical University Davutpaşa Campus Civil Engineering Faculty. Using VRS and FKP technique, GPS data were collected for 10 minutes in total, with the first 4 minutes and the last 4 minutes still, 2 minutes moving. Data was collected at a sampling rate of $20 \mathrm{~Hz}$.

In the VRS method, the oscillation frequency was determined as $5.00 \mathrm{~Hz}$ and the amplitude was $16 \mathrm{~mm}$ according to the LVDT results of shake table. In the FKP method, the oscillation frequency was determined as $5.00 \mathrm{~Hz}$ and the amplitude was 17 $\mathrm{mm}$ according to the LVDT results of shake table.

GPS-derived data were analysed using time series analysis and Fast Fourier Transform. The time series analysis is based on the time series of the system observed in successive intervals; separates trend, periodic and irregular movements, reveals the properties of the system, defines the system and is frequently applied especially in non-parametric situations. The information provided by the dynamic structure is important in order to control the system represented by the series and to make accurate predictions about the future. In the time series analysis, firstly, the time-dependent graph is created and then the periodical and the stochastic components are analysed by sera to eliminate the serigraph (Erdoğan, 2006).
Changes observed in increasing or decreasing trends due to any factor such as natural effects or impairment of homogeneity by human influence in successive observations are called trends (Erdoğan, 2006; Tülücü 1996). To extract the trend component from series, a time-correlated linear equation $(\mathrm{YT}=\mathrm{a}+\mathrm{b} . \mathrm{t})$ is obtained with the Least Squares Method. The coefficients of the obtained equation are calculated by regression analysis (Erdoğan, 2006).

Trendless series and graphs were created by separating the calculated trend from the series. (Figure 2 and Figure 3). Then spectral analysis was carried out to determine the frequency and amplitude of the series.

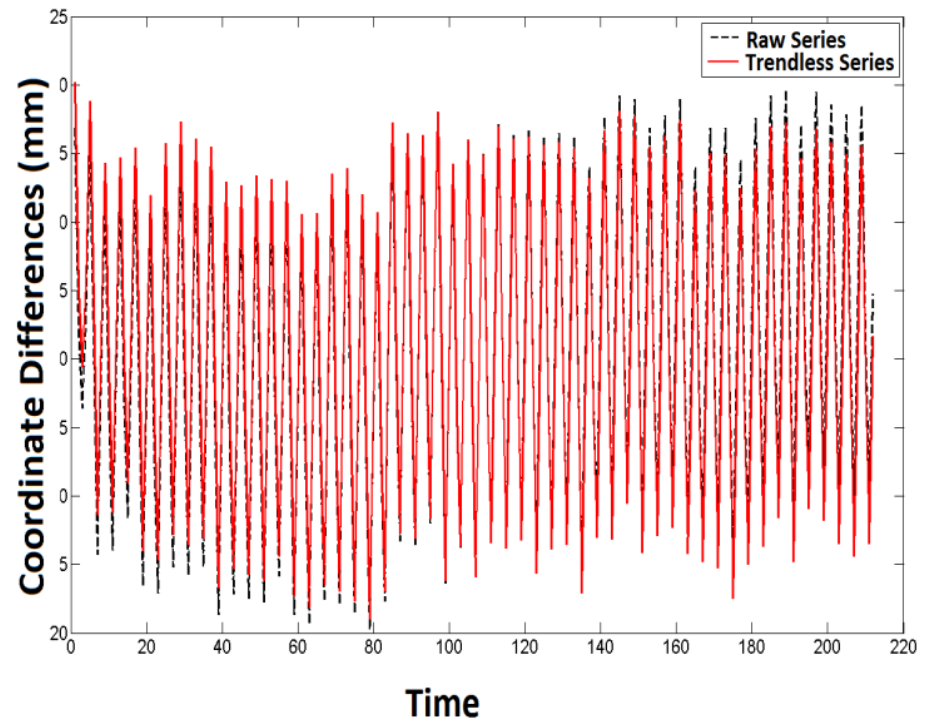

Figure 2. Trendless Time Series of VRS Method

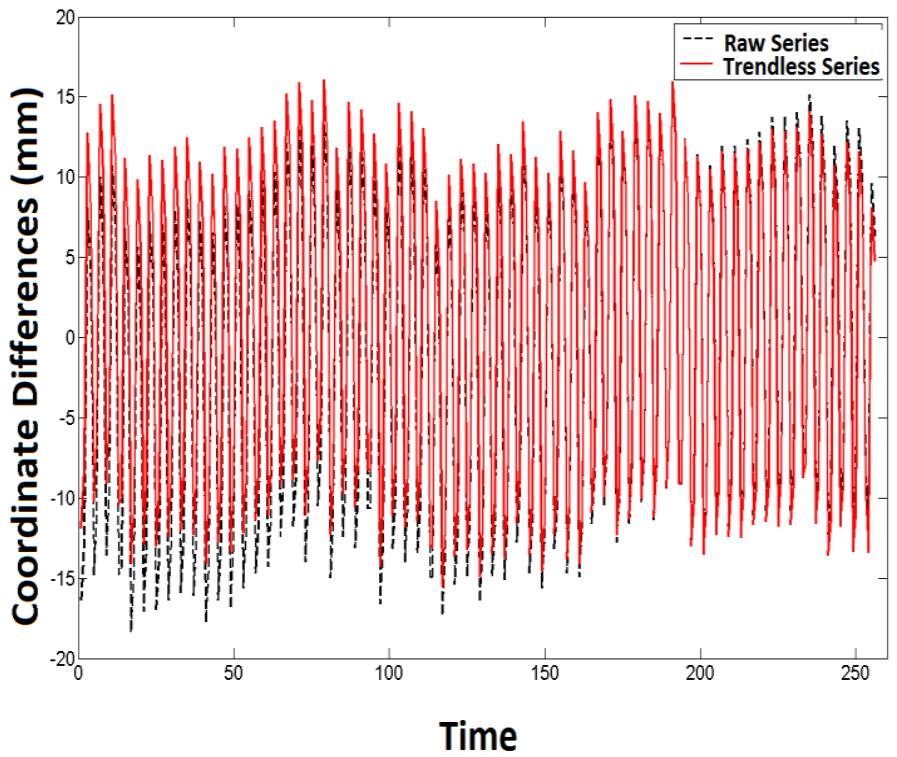

Figure 3. Trendless Time Series of FKP Method

The spectral analysis method reveals the frequency domain analysis of the time series. Time and frequency domain analyses complement each other and the same information gives different 
ideas about the nature of the time series in different ways. For this reason, the conversion from the time domain to the frequency domain is performed by Fast Fourier Transform (Erdoğan ,2006).

Frequency and amplitude values for motion after Fast Fourier Transform applied to the time series were found to be $5 \mathrm{~Hz}$ and $14.6 \mathrm{~mm}$ for VRS, $5 \mathrm{~Hz}$ and $15 \mathrm{~mm}$ for FKP. Graphs of these values were obtained (Figure 4 and Figure 5).

\section{LVDT}

\section{Amplitude:16 mm Frequency:5 Hz}

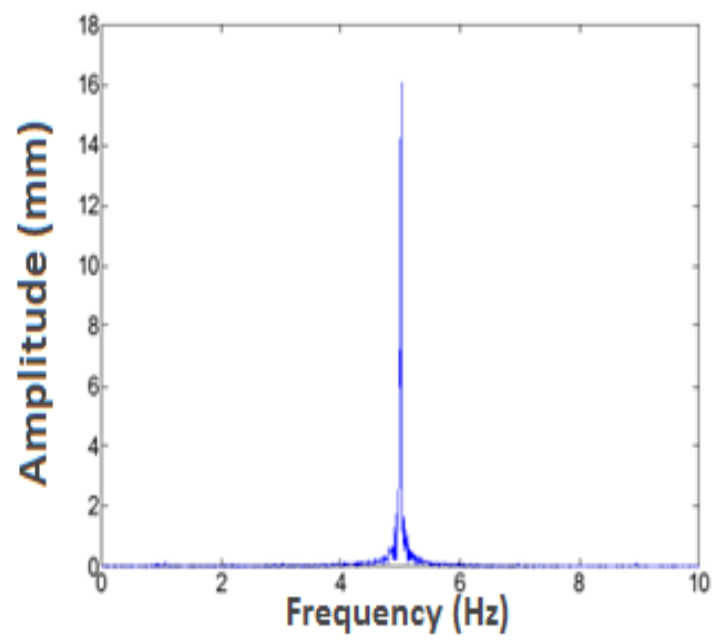

Amplitude:14.6 mm Frequency:5 Hz

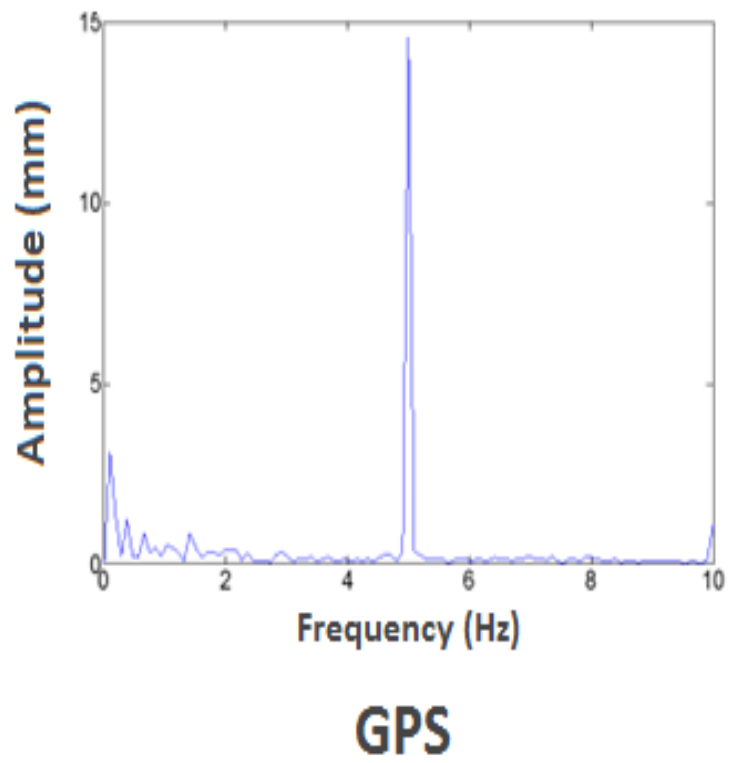

Figure 4. VRS Method Comparison of LVDT and GPS Frequency-Amplitude Values

In both measurement methods, frequency values can be determined with high accuracy. Compared to the values of this amplitude LVDT, it can be seen that the true value is reached at a difference of $1.5 \mathrm{~mm}$ for VRS and $2 \mathrm{~mm}$ for FKP. Since this margin of error remains within the measurement accuracy limits of the RTK GPS method, it is seen that the desired accuracy is achieved at the end of the application. The accuracy of the results is very high because the internal accuracy of the data can be determined with precision down to centimetre.

\section{LVDT}

\section{Amplitude:17 mm Frequency:5 $\mathrm{Hz}$}

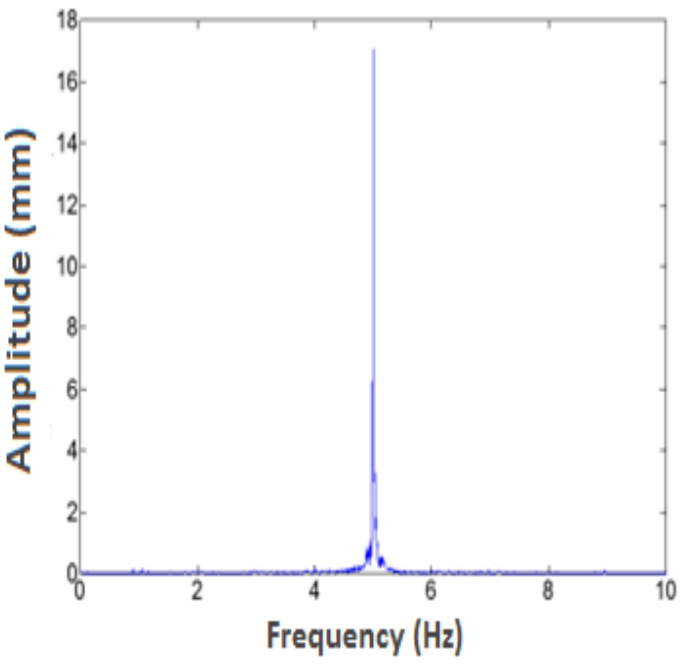

\section{Amplitude: $15 \mathrm{~mm}$ Frequency:5 $\mathrm{Hz}$}

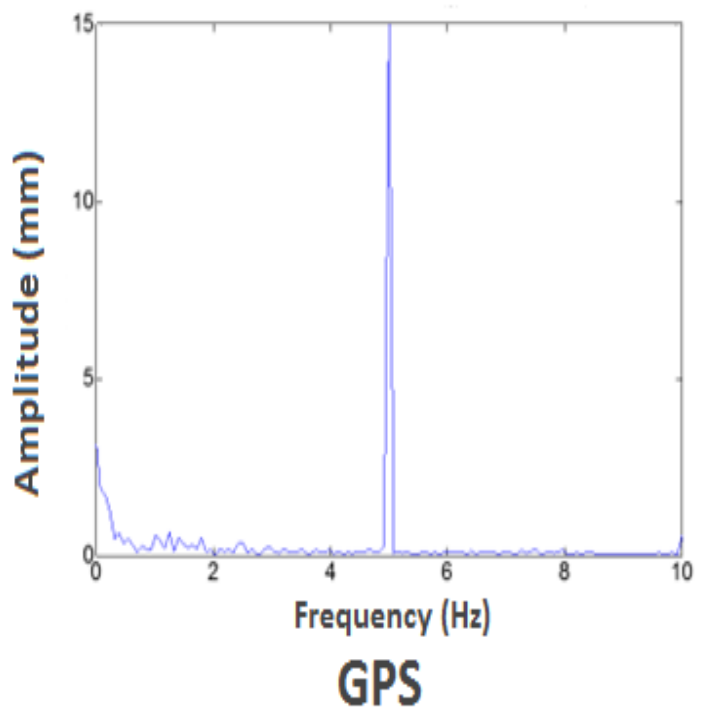

Figure 5. FKP Method Comparison of LVDT and GPS Frequency-Amplitude Values

\section{CONCLUSIONS AND RECOMMENDATIONS}

In this study, RTK GPS technology, one of the structural health monitoring methods, has been implemented in order to prevent disasters and provide the least possible loss in case of a disaster. 
As a result of this application; the effectiveness of the RTK GPS VRS and FKP measurement methods has been proven to be effective in monitoring the structures.

The RTK GPS measurement method has been found to be effective in construction health monitoring, effective availability in simultaneous data acquisition and instantaneous location information after evaluation.

It is seen that the VRS measurement method gives more realistic results when the two methods are compared with each other.

It has been shown that RTK GPS measurement method is a highly accurate alternative to other structural health monitoring methods and it is possible to use simultaneous evaluation and status determination by means of instant positioning method and it can be used effectively in the context of Structural Health Monitoring.

It is also predicted that more effective results can be obtained by constructing a hybrid measuring system by combining the measurements made with the accelerometer and the RTK GPS measuring method.

\section{REFERENCES}

Arslan, N., Aydın, N., Üstün, A. and Demirel, H., (2002). Sanal Referans İstasyonu Sistemi (VRS), Selçuk Üniversitesi Jeodezi ve Fotogrametri Mühendisliği Öğretiminde 30. Y1l Sempozyumu, Konya

Erdoğan H. (2006). Mühendislik Yapılarındaki Dinamik Davranışların Jeodezik Ölçmelerle Belirlenmesi, Doktora Tezi , Yıldız Teknik Üniversitesi, Fen Bilimleri Enstitüsü, İstanbul.

Eren, K., Uzel, T., Gülal, E., Yıldırım, O. and Cingöz, A., (2009). "Results from a Comprehensive GNSS Test in the CORS-TR Network: Case Study', Journal of Surveying Engineering, 135(1): 10-18.

Im,S.B, Hurlebaus, S. M.ASCE; \& Kang,Y.J. M.ASCE (2013) Summary Review of GPS Technology for Structural Health Monitoring. J. Struct. Eng. 2013.139:1653-1664.

Önen, Y. H., Dindar, A. A., Gülal, E., Gürkan, G., Gürkan, K. and Akpınar, B., (2014). "Use of High-Frrequency GNSS Sebsors in Dynamic Motions', Second European Conference on Eartquake Engineering and Seismology, 25-29 Ağustos, İstanbul.

Tülücü, K., (1996), Uygulamalı Hidroloji, Ç.Ü. Ziraat Fakültesi, Genel Yayın No.138, Adana

Wang, G., Blume, F., Meertens, C., Ibanez, P. and Schulze, M. (2012). 'Performance of High-rate Kinematic GPS During Strong Shaking: Observations from Shake Table Tests and The 2010 Chile Earthquake', Journal of Geodetic Science, 2(1): 15 30.

Wells, D.E., Beck, N., Delikaraoğlu, D., Kleusberg, A.,Krakiwsky, E. E., Lachapelle, G., Langey, R.B., Nakiboğlu, M., Schwarz, K.P., Tranquilla, J.M., Vanicek, P., (1987). Guide To GPS Positioning, Second Edition, Canadian GPS Associates, New Brunswick, Canada. 